\title{
APPLICATIONS OF MULTI-CRITERIA DECISION ANALYSIS IN THE SELECTION OF FOREIGN MARKETS TO EXPORT
}

\author{
Angela Reyes \\ Department of Industrial Engineering \\ Universidad de los Andes \\ Bogota, Colombia \\ E-mail: b-reyes@uniandes.edu.co \\ Diana Lesmes* \\ Department of Industrial Engineering \\ Universidad de los Andes \\ Bogota, Colombia \\ E-mail: lu-novoa@,uniandes.edu.co \\ Mario Castillo \\ Department of Industrial Engineering \\ Universidad de los Andes \\ Bogota, Colombia \\ E-mail: $\underline{\text { mcastill@ } \text { uniandes.edu.co }}$
}

\begin{abstract}
This work makes a formal comparison of three Multi-Criteria Decision Analys is models for selecting export markets for Colombian Small and Medium Enterprises that produce software services. The results help to identify the differences among the models (ANP, MAUT, Organization Empirical Model) in a specific case, with a high level of accuracy, and illustrate the advantages and disadvantages of each model.
\end{abstract}

Keywords: Analytic Network Process, Multi-Attribute Utility Theory, Small and Medium Enterprises

\section{Introduction}

The software industry is nowadays one of the sectors with the highest growth potential in Colombia. One of the main interests of this industry is to export services since there is government support and low-cost high-quality human resources. For those reasons, Proexport -the Colombian trade promotion organization- and the Colombian Department of Commerce, Industry and Tourism have developed programs to help Small and Medium Enterprises (SMEs) export their services. The objective of this research is to make a formal comparison of three Multi-Criteria Decision Analysis models for selecting export markets for Colombian Small and Medium Enterprises that produce software services. The results help identify the differences among the models (ANP, MAUT, Organization Empirical Model) in a specific case, with a high level of accuracy, and illustrate the advantages and disadvantages of each model.

First, this article presents the structured methodology developed to apply and compare export market selection models. Then, the models developed are presented (MAUT, ANP and the Organizational Empirical Model). The performance of the models is then compared based on their constraints, results,

\footnotetext{
* Corresponding author
} 
understandability (simplicity and practicality), implementation time and scalability. Finally, conclusions are presented.

\section{Objectives}

The main objective of this research was to develop a structured methodology to implement and compare export market selection models for SMEs. The specific objectives were: to structure the ANP and MAUT market selection models, and to analyze the advantages and disadvantages of each method.

\section{Methodology}

The methodology developed to implement and compare the export market selection models consists of seven stages. The sequence is summarized in Figure 1.

\section{To structure the models}

- To describe the decision and to identify the company's objectives.

-To identify alternatives, aspects and criteria.

\section{To develop the models}

- To develop the ANP model.

- To develop the MAUT model.

\section{To obtain results}

- To obtain the models ranking of alternatives.

- To perform sensitivity analysis with both Decision Theory methods.

\section{To compare results}

-According to: implementation time, alternatives ranking, constraints satisfied, scalability and easiness to implement.

\section{To produce conclusions}

Figure 1. General methodology used for models development

\section{Methodology application}

The methodology was applied to a specific software company. The most important results of the application in the main stages of the methodology are described below.

\subsection{Models developed}

The company carried out a market research in order to identify the initial group of countries to be evaluated. These countries were Argentina, Brazil and United States. The three models evaluated the alternatives based on the same six aspects and eighteen criteria. The aspects considered were the macroeconomic component, the commercial component, the commercial policy, communication, target market and logistics. 
The MAUT structure is presented on the left side of Figure 2. The methodology used to develop the MAUT model was based on three steps: obtaining single utility functions, calculating weights and evaluating the multi-attribute utility function. In order to obtain single utility functions, the proportional scores method was used if the attribute was quantitative, and ratio was used if it was qualitative. All single utility functions are calculated in a linear form. In order to calculate weights, the swing weighting method was used. Finally, the additive utility function was calculated for each alternative. This model assumes that the criteria are independent. It was developed in Hiview from Catalyze.
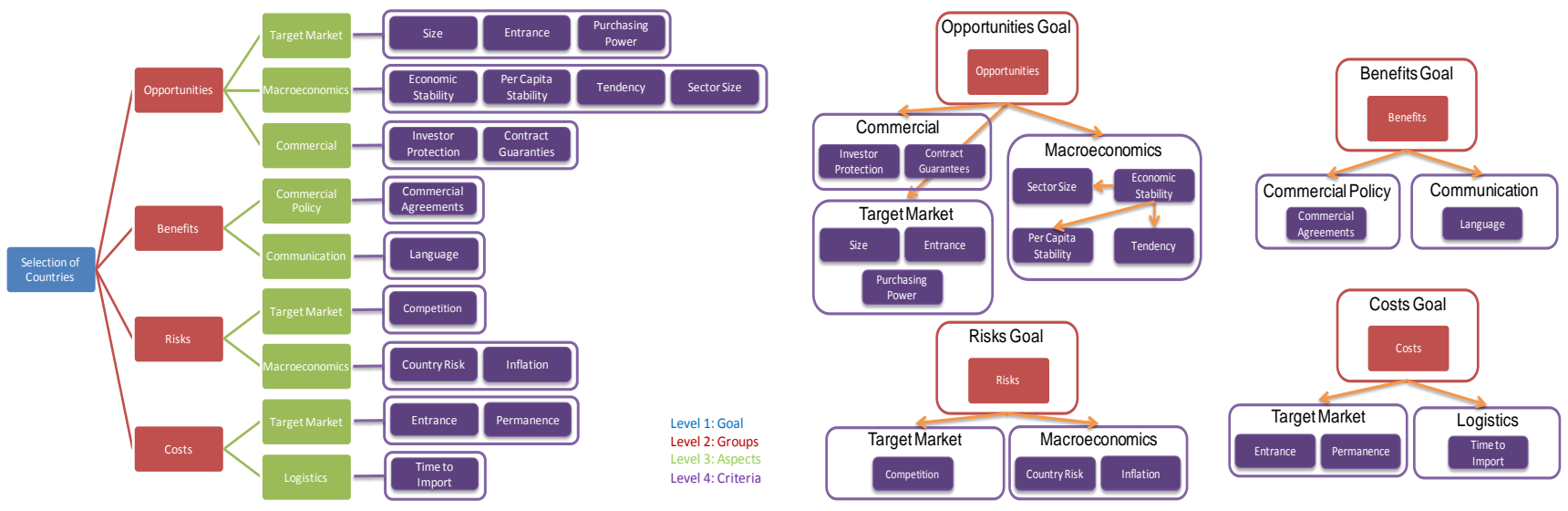

Figure 2. Models developed using MAUT and ANP

The structure of the model developed using ANP was shown on the right side of Figure 2. Since ANP is not constrained by criteria independence, it was possible to consider the criteria dependence relation in the macroeconomic component. There is a dependence relation because stability was measured through GDP, influencing the following: tendency because it was measured using GDP growth, per capita stability because it was measured using per capita GDP, and sector size because it was measured using the service sector GDP percentage in relation to the country GDP. The software used to develop the model was Super Decisions from Bill Adams and the Creative Decision Foundation.

\subsection{Results}

The MAUT application results are shown on the left side of Figure 3. As it can be seen in the figure, the country with the highest utility was United States (86) due to its excellent performance in the Opportunities aspect. Brazil (18) had a slightly better utility than Argentina due to its good performance in the Opportunities aspect. Argentina (14) was the third alternative; its performance in the Opportunities and Benefits aspects was similar.

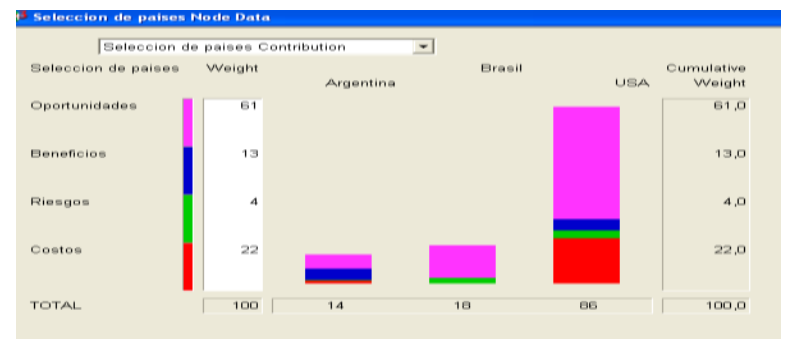

\begin{tabular}{|c|c|c|c|c|}
\hline Name & Graphic & Ideals & Normals & Raw \\
\hline Argentina & & -0.006857 & $\mid-0.006639$ & -0.004394 \\
\hline Brasil & & -0.026075 & -0.025244 & -0.016710 \\
\hline USA & & 1.000000 & 0.968117 & 0.640815 \\
\hline
\end{tabular}

Figure 3. MAUT and ANP results 
The ANP results were shown on the right side of Figure 3. According to these results, the best alternative was USA, followed by Argentina and, last of all, Brazil. This model showed that the risks and costs of entering the software market in Argentina and Brazil exceeded the benefits and opportunities that could be gained, considering the merits priorities established by the decision maker. Note that for all the models the Benefits, Opportunities, Cost and Risks weights were the same.

Proexport model ranked USA $(4,73)$ as the best alternative, followed by Brazil $(3,37)$ and, last of all, Argentina $(3,25)$. To calculate the countries ranking, the decision maker assigned weights to the aspects and then distributed the weights of each aspect among its criteria; in the end, the weight of all the criteria added up $100 \%$. Next, the decision maker rated the performance of each country based on the evaluation criteria. According to Proexport's methodology, the rating is a subjective value between 1 and 5, with 1 being the worst score and 5 the best. Finally, the ratings multiplied by the importance of each aspect were added up. As a result, the ratings per country were obtained.

\subsection{Se nsitivity analysis}

The MAUT comparative sensitivity analys is is shown on the left side of Figure 4. Green color indicates that if the weight of a specific criterion were increased by more than 15 points, the best alternative would be the other country that is shown in the figure. If, for example, the weight of Market Tendency and Language were increased by more than 15 points, the best alternative would be Argentina. Likewise, if the weight of Competition Risks or Purchase Ability were increased, the best alternative would be Brazil.
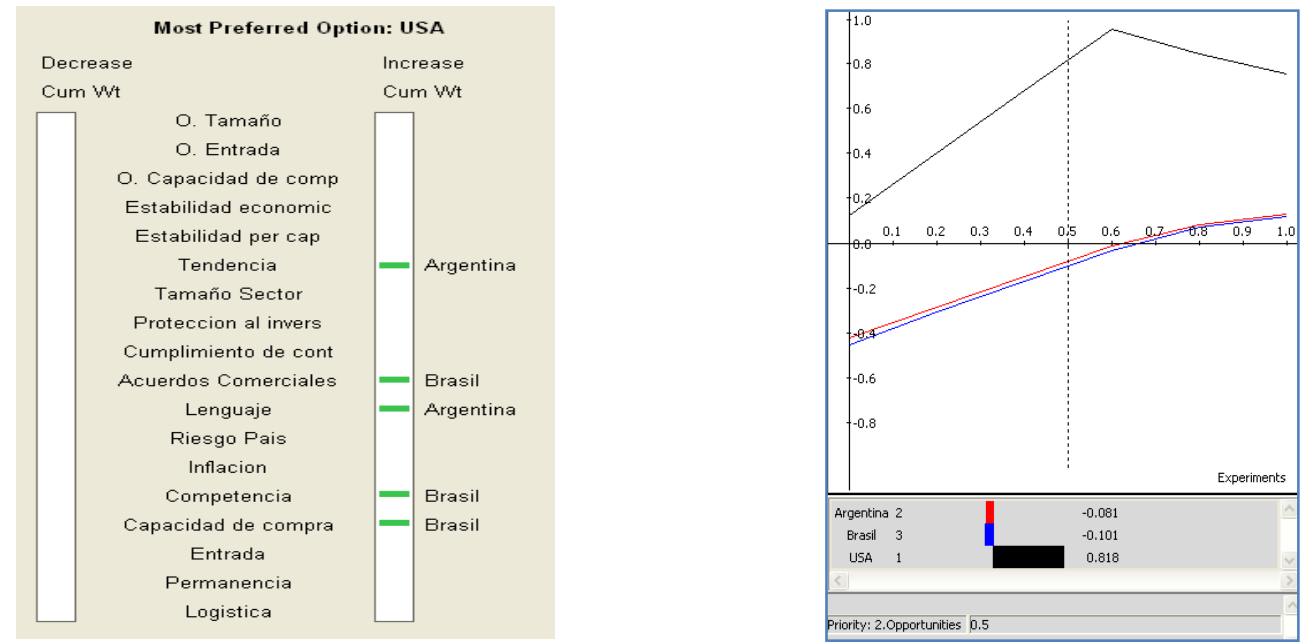

Figure 4. MAUT and ANP Sensitivity Analys is

The ANP sensitivity analysis was shown on the right side of Figure 4. If the Opportunities were given a weight higher than 0.65 , the performance of all the countries becomes positive, and the order will always be the same (USA first, Argentina second and Brazil third).

\section{Models comparison}

Figure 7 presents a comparison of the performance of the MCDA models based on constraints, results, understandability, implementation time and scalability.

MAUT's additive function used to calculate the performance of the alternatives assumes independence among same level attributes or criteria. This constraint was violated because the macroeconomic criteria 
were related. In contrast, the ANP does not assume criteria independence. Proexport's model constrains have not been considered.

The ranking of the alternatives of the models developed with MAUT and Proexport's market selection matrix were the same, while the order of Brazil and Argentina was interchanged when the ANP model was implemented. With respect to the alternatives ranking, the ANP model complements results because it not only ranked the alternatives but also identified those that could produce negative results for the company. In addition, it permitted to check the consistency of the judgments, ensuring the reliability of the ANP results.

\begin{tabular}{|c|c|c|c|c|}
\hline \multicolumn{2}{|c|}{$\begin{array}{l}\text { MCDA Models } \\
\text { Comparison }\end{array}$} & ANP & MAUT & Proexport \\
\hline \multicolumn{2}{|c|}{ Model Constraints } & - & $\begin{array}{l}\text { Independence } \\
\text { restriction unsatisfied }\end{array}$ & - \\
\hline \multirow{3}{*}{$\begin{array}{l}\text { Alternatives } \\
\text { Ranking }\end{array}$} & USA & 0,968 & 86 & 4,730 \\
\hline & Brazil & $-0,025$ & 18 & 3,372 \\
\hline & Argentina & $-0,006$ & 14 & 3,246 \\
\hline \multicolumn{2}{|c|}{$\begin{array}{l}\text { Understandability } \\
\text { (the method is simple } \\
\text { to use and practical) }\end{array}$} & Low & Medium & High \\
\hline \multicolumn{2}{|c|}{$\begin{array}{l}\text { Implementation Time } \\
\text { (without model } \\
\text { structuring and data } \\
\text { gathering) }\end{array}$} & $49 \mathrm{~min}$ & $29 \mathrm{~min}$ & $17 \mathrm{~min}$ \\
\hline \multicolumn{2}{|c|}{ Scalability } & $\begin{array}{l}\text { The number of } \\
\text { comparisons increases } \\
\text { substantially }\end{array}$ & $\begin{array}{l}\text { Weight assignations } \\
\text { increase moderately }\end{array}$ & $\begin{array}{l}\text { Weights assignations } \\
\text { increase moderately }\end{array}$ \\
\hline
\end{tabular}

Figure 7. Results comparison

In this particular application, the decision maker found difficulties when making ANP's pairwise components comparisons because of the lack of clarity in the comparisons that were made. Regarding the practicality, MAUT's single utility functions calculations did not demand the decision maker participation because the data from the attributes was used to measure those utilities. Additionally, MAUT's swing weighting method was praised by the decision maker because of its simplicity and practicality. Furthermore, this method made possible for the decision maker to assign judgments based on his preferences, avoiding bias towards a specific alternative. However, Proexport's model was easier to implement because it did not require any known measurement scales.

The differences among the models implementation time was very small for a decision of this importance, therefore it was considered irrelevant. Finally, the MAUT and Proexport's models scalability was better. Therefore when implementing the ANP, it is advisable to select only the alternatives that must be evaluated with the model in order to maintain a good level of accuracy in the analysis.

\section{Conclusions}

The ranking of the alternatives using the ANP model differs from the other two models. This could have happened due to the dependence relations of the criteria in the macroeconomic component in the Benefits sub-network. For this reason, it is important to continue this work developing the MAUT model with a multiplicative utility function or a multi-linear utility function since they are not constrained by the independence assumption. 
ANP performance was low regarding understandability and scalability. However, penalizing the model due to those criteria could be a mistake if the best markets ranking is the one suggested by the ANP. A possible solution to overcome this problem would be to offer training for the decision makers to assign judgments on the pairwise comparison matrices.

An advantage of the ANP and MAUT models is that they are structured through a clear definition of aspects and criteria, while Proexport's model requires the identification of variables. The advantage of using criteria instead of variables is that the conceptual model can be adapted to any type of company in the software sector. Another advantage of the ANP and MAUT models is that the ir results are more trustworthy for the decision makers because they are based on mathematical models theoretically supported. In conclusion, ANP and MAUT perform better than Proexport's model. Besides, both models enhance results with the possibility to perform sensitivity analysis.

\section{REFERENCES}

Bouyssou, D. (2006). Evaluation and decision models with multiple criteria: stepping stones for the analyst. New York: Springer.

Casillas Bueno, J. C. (2002). Factores determinantes de la localización de las IDE de las empresas españolas. Revista europea de dirección y economía de la empresa, 115-128.

Castillo Hernández, M. (2006). Toma de decisiones en las empresas: entre el arte y la técnica: metodologías, modelos y herramientas. Bogota: Ediciones Uniandes.

Chicaiza, L. (16 de Junio de 2010). Exportación de Software. (A. B. Reyes Rico, Entrevistador)

Clemen, R. T., \& Reilly, T. (2001). Making hard decisions: with DecisionTool. Belmont, CA.: Duxbury Press, Thomson Learning.

Dyer, J. S., Edmus, T., Butler, J. C., \& Jia, J. (s.f.). A Multiattribute Utility Analysis of Alternatives for the Disposition of Surplus Weapons-Grade Plutonium.

Elmisalami, T., Walters, R., \& Jase, E. J. (s.f.). Construction It Decision Making Using Multiattribute Utility Theory For Use In A Laboratory Information Management System.

Federación Colombiana de la Industria de Software. (2001). Descripción Del Sector Del Software. Bogota.

Grass, S. I. (2005). Model Word: The Great Debate, Muat versus AHP. Interfaces, 308.

Kaliszewski, I. (2006). Soft computing for complex multiple criteria decision making. New York: Springer.

Lesmes, D., Cendales, C., \& Buitrago, L. (2009). Application of the Analytic Network Process (ANP) to Select New Foreign Markets to Export Software Services: study of Colombian Firms. ISAHP proceedings. Pittsburgh, Pennsylvania, USA. ISSN 1556-8296. 
Papadopoulos, N., \& Denis, J. (1988). Inventory, Taxonomy and Assessment of Methods for International Market Selection. International Making Review, 38-51.

Ralph, K., \& Howard, R. (1994). Decisions with multiple objectives: preferences and value tradeoffs. Cambridge, UK: Cambridge University Press. 